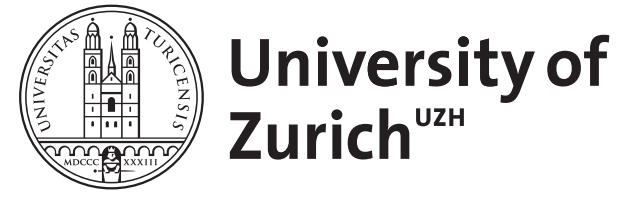

\title{
Contextualism and the use-mention distinction
}

\author{
Riegelnik, Stefan
}

\begin{abstract}
The use-mention distinction is considered as a fundamental concept in the philosophy of language. So it goes without doubt that a comprehensive theory of language has to account for this distinction. In this paper I explore what it means to account for such a distinction and I argue that the main ideas of contextualist theories of language are in conflict with the distinction in question.
\end{abstract}

DOI: https://doi.org/10.2478/v10016-011-0015-4

Posted at the Zurich Open Repository and Archive, University of Zurich

ZORA URL: https://doi.org/10.5167/uzh-97300

Journal Article

Published Version

Originally published at:

Riegelnik, Stefan (2011). Contextualism and the use-mention distinction. Lodz Papers in Pragmatics, $7(2): 281-290$.

DOI: https://doi.org/10.2478/v10016-011-0015-4 


\author{
Štefan Riegelnik* \\ Vienna University of Economics
}

\title{
CONTEXTUALISM AND THE USE-MENTION DISTINCTION
}

\begin{abstract}
The use-mention distinction is considered as a fundamental concept in the philosophy of language. So it goes without doubt that a comprehensive theory of language has to account for this distinction. In this paper I explore what it means to account for such a distinction and I argue that the main ideas of contextualist theories of language are in conflict with the distinction in question.
\end{abstract}

\section{Keywords}

use-mention distinction, contextualism, minimalism, truth-conditional semantics.

\section{Introduction}

The use-mention distinction is considered as one of the fundamental concepts in the philosophy of language. Its fundamentality might be explained by the fact that it is more than questionable whether an inquiry into the working of natural languages is possible without such a distinction. Since the distinction comes to application in ordinary speech as well ("Now" means now!), a theory of language is legitimately expected to account for this distinction. But what is it exactly that a theory of language should account for? A preliminary characterisation might go as follows: We use expressions such as words and sentences to say something about an object and in some cases the object in question is an expression. In the former case we say that the expression is used, in the latter that it is mentioned. As

\footnotetext{
* Philosophy Division

WU (Wirtschaftsuniversität Wien)

Vienna University of Economics and Business

Augasse 2-6, 1090 Vienna, Austria

e-mail: Stefan.Riegelnik@wu.ac.at
} 
obvious as this characterisation seems to be, it runs quickly into difficulties: since a mentioned expression is used as well - namely used to be mentioned - a more elaborated definition is necessary in order to draw a sharp line between the one and the others. But it is sufficient for my purpose - my intention is not to find a waterproof definition for using and mentioning and what distinguishes them but to explore the compatibility of the distinction between using and mentioning an expression on the one side and theories of language, which impose a decisive role to an utterance's context, on the other side. My thesis is that the main ideas of these theories, often referred to as contextualism, are in conflict with the distinction in question.

The contextualists' main idea is that sentences carry content only in a particular context of a speech act. According to them, the reason for putting forward speech acts is justified by the fact that an utterance's context determines its truth conditions beyond the mere assignment of the referents of so called indexical expressions such as I, here, now and other forms of saturation. Contextualists hold that the propositional contribution of all expressions is determined by the context, or as Recanati puts is:

Contextualism generalizes context-sensitivity: it claims that sentences carry content only in the context of a speech act. (Recanati 2005:1)

This claim precludes, too, that "we may legitimately ascribe truth-conditional content [...] to natural-language sentences [...]" (Recanati 2004: 83). Thus, one might intervene here and argue that from a contextualist's point of view to account for the use-mention distinction of expressions just is not necessary because the distinction must be drawn on the level of speech acts, viz. between acts and the talk about acts. As a first consequence, the initial characterization should be amended in such a way that if language turns to itself, we do not refer to expressions but to speech acts. In other words, if speech acts are the primary bearers of content and sentence's meaning does not play a role in communication, contextualists can lean back. But it is not as easy as it seems, since even the most radical contextualists cannot dispense with sentences or a similar notion. I will spell this out later.

\section{The meaning of mentioned expressions}

The discussion of the use-mention distinction is closely related to the discussion of quotations. Though it is true that mentioned expressions are often identified by quotes, it would be misleading to reduce mentioned expressions to quoted expressions. Neither is quotation the only - though primary - device used to refer to an expression nor are all quoted signs mentioned expressions. This is 
Lodz Papers in Pragmatics 7.2 (2011)/Special Issue on Context and Contextualism: 280-290 DOI: $10.2478 / \mathrm{v} 10016-011-0015-4$

supported by the fact, too, that not all quoted shapes are meaningful, but it is questionable whether meaningless shapes and signs are to be considered as expressions at all. One might extend this point and thereby bringing the debate to an end by arguing that mentioned expressions are for whatever reason not meaningful and, in consequence, not subject to a theory of meaning at all. But it is sufficient to appreciate that mentioned expressions are expressions of a particular natural language such as English or Italian, too. Thus claiming that mentioned expressions are not meaningful at all commits one to the view that there is no difference between the following:

(1) "adsfa" is not an English sentence.

(2) "Siamo qui" is not an English sentence.

(3) "John is ready" is an English sentence.

But there are differences: (1) is true because we do not regard adsfa as a meaningful expression - rather as a bunch of arbitrary letters - and since adsfa is not considered to be meaningful, it is neither an expression nor a (English) sentence or word. Wittgenstein makes this point explicit in the opening remarks of his Philosophical Grammar, which I quote at some length:

How can one talk about 'understanding' and 'not understanding' a proposition? Surely it is not a proposition until it's understood?

Does it make sense to point to a clump of trees and ask "Do you understand what this clump of trees says?" In normal circumstances, no; but couldn't one express a sense by an arrangement of trees? Couldn't it be a code?

One would call 'propositions' clumps of trees one understood; others, too, that one didn't understand, provided one supposed the man who planted them had understood them.

Doesn't understanding only start with a proposition, with a whole proposition? Can you understand half a proposition? (Wittgenstein 1974: 5)

The gist of these remarks is that we would not recognize a sentence or an expression as a sentence or as an expression if it were not understood or meaningful. It is true that adsfa might become an (meaningful) expression, for instance, if one uses the expression and explains how adsfa ought to be used, but even this presupposes that something becomes meaningful, e.g. by an explanation how it should be used. (2) is true, though siamo qui is not an English sentence, but for those who understand English and Italian it is true. (3) is obviously true, since John is ready is meaningful and it is an English sentence. One might draw a line, too, by alluding to the difference between a mere list (ready is John) and 
expressions, which exhibit a unity (John is ready). I doubt that the difference between them and the unity of the latter could be explained without appealing to some higher linguistic notion, but I am not going into this here.

A note of clarification might be at place here: it does not follow from these considerations that mere mentioning makes expressions meaningful. Neither is my plan to discuss the workings of meta-representational operators here nor the criteria for the individuation of words, i.e. flat mention ("bulb" has four letters) is left out here, too. I narrow down my examination to mentioned sentences such as John is ready and I consider clarifying how the meaning of a mentioned expression is determined as a constitutive part of an account of the use-mentioned distinction. The question shows some affinity to some quotation theories, in particular to those which explain quotation by appeal to the notion of reference. Recanati writes:

What is the reference of a quotation? Is it a linguistic expression as such, or a brute shape? Is it a type or a token? It is possible to quote meanings or contents as well as forms of words? (Recanati 2001: 637)

At any rate, it is legitimate to expect a satisfactory theory of language to account for the meaning of mentioned expressions such as John is ready.

\section{The use-mention distinction and theory of meaning}

But is this true? Is it really legitimate to ask what the meaning of a mentioned expression is? The question might suggest that there is an anomaly in determining the meaning of a mentioned expression or that it differs significantly from the meaning of a used expression. If we consider how the meaning of a mentioned expression could be given or what a first step toward an explanation would be -

(4) "John is ready" means that John is ready.

(5) "John is ready" is true if and only if John is ready.

- it becomes pretty clear that the explanation of the meaning of a mentioned expression is what one would say is what a theory of meaning aims at: to give the meaning of (every) meaningful expression. The quoted words in (4) are mentioned and the word(s) on the right hand of the operator means should give the meaning of John is ready. Although the operator means does not do the job very well especially not for a theory of meaning - it is clear that no matter what operator or predicate stands between the expression mentioned on the left side and the meaning-giving something on the right side, to explain the transition from a mentioned expression to its meaning is the very task of a theory of meaning. Having said that, one might again bring the debate to an end by arguing that the 
Lodz Papers in Pragmatics 7.2 (2011)/Special Issue on Context and Contextualism: 280-290 DOI: 10.2478/v10016-011-0015-4

question "What is the meaning of the mentioned expression $X$ ?" does not reveal any particularity and should be understood as "What is the meaning of the expression $X$ ?" as long as we bear in mind to find an operator which explains disquotation. However, it leaves the question for the nature of the use-mention distinction unsettled, in particular because it leaves open the question for the nature of mentioned expressions. After all, what has been shown thereby and so far is that the question for the meaning of a mentioned meaning cannot be settled isolated from the "ordinary" way the meaning of (used) expressions is determined. But what follows from this truism?

Let us try a different approach by reflecting on the use-mention distinction from a particular theory's point of view. I expect no objection that according to the general scheme (feel free to chose your own scheme) -

(6) “ $X$ ” means (that) $p$.

the meaning of

(7) "John is ready"

is given by a statement such as

(8) "John is ready" means that John is ready.

or according to the basic scheme of truth-conditional semantics

(9) "John is ready" is true if and only if John is ready.

What I want to point out is that since the options are limited - (7) is in isolation, without any further information about the person John or his readiness - the potential answers are statements such as (8) respectively biconditional statements such as (9). (7) is in the first place an example used to discuss the nature of mentioned expressions and it is not even in question if and what further propositions could be expressed by an utterance of John is ready (if this makes sense at all) - yet it is meaningful otherwise we would not recognize it as an expression. This should not distract us from asking for a legitimacy of (8) or (9), which has to be found, of course, elsewhere. A legitimacy for (9) might go as follows: If we build a theory of meaning on the interdependency of truth and meaning we do so because we have good reasons to assume the correctness of this interdependency and there is no reason not to apply it on examples such as (7). But again, it goes without doubt that it is not an advancement to postulate (8) or (9) in order to answer the question for the meaning of (7), especially if the nature of the 
use-mention distinction comes under scrutiny. What is it, what we are talking about when we talk about (7)? Is (7) a sentence-type? A token? A skeleton? I leave this question open, mainly because I do not think that an answer could be given at this stage without presupposing too much. Since I am concerned with the usemention distinction and its compatibility with some fundamental features of contextualism, I turn to proponents and opponents of such theories. I begin with a glance at the latter.

\section{The use-mention distinction and the minimalism versus contextualism debate}

In Insensitive Semantics (2005), Cappelen and Lepore as minimalists argue that some types of communication would not be possible if contextualism were true. Their reductio argument, if correct, shows that contextualists cannot account for "communicating across diverse contexts of utterance" (Cappelen and Lepore 2005: 123). Prima facie evidence that communication across contexts in fact succeeds are so-called indirect speech reports such as:

(10) Barbara said that John is ready.

Cappelen and Lepore argue that this kind of cross contextual communication would not be possible if contextualism were true, since contextualists hold that the propositional contribution of all expressions is determined by the context, or as Recanati puts it:

Contextualism generalizes context-sensitivity: it claims that sentences carry content only in the context of a speech act. (Recanati 2005: 1)

The crucial question for the contextualists is how it is possible that we report what someone has said in a radically different context if the meaning is determined by the context of utterance? Cappelen and Lepore offer them two alternatives: either they cannot account for indirect speech reports or accounting for indirect speech reports would commit them to admit that minimal propositions play a role in communication, which is inconsistent with the contextualist's principle.

Their reason for drawing on indirect speech reports is twofold: First, it serves as a vehicle to reveal inconsistencies in contextualism. Secondly, it serves as a criterion or test for the semantic context-sensitiveness of an expression. According to the test, an expression is context-sensitive, if it blocks indirect speech reports. To give an example: since a friend cannot report my utterance of I am Stefan as Stefan said that I am Stefan, I is context-sensitive. The test aims at showing that 
Lodz Papers in Pragmatics 7.2 (2011)/Special Issue on Context and Contextualism: 280-290 DOI: $10.2478 / \mathrm{v} 10016-011-0015-4$

semantic context-sensitivity is restricted to a small set of expressions (mainly indexical expressions). Although minimalists agree that there are indefinitely many ways to satisfy truth conditions of (7), they claim that no matter how different the contexts of utterance of (7) are, all utterances of (7) share a minimal (semantic) content. Minimal propositions represent thus the context-independent part of an utterance, i.e. that part of an utterance, which does not vary from context to context. The essence of minimalistic accounts such as Cappelen's and Lepore's is that we legitimately ascribe truth-conditional content to sentences such as (7), thus, in the first place, mentioned sentences are considered as having content at all. In other words, putting the meaning of mentioned sentences on a par with minimal propositions is a viable alternative (I leave out indexical expressions in this sketch).

Contextualists hold the contrary. Although there is not one version of contextualism, the appeal to contextual contributions in order to explain the meaning of an utterance is an integral part of contextualist's theories. In their discussion of a general picture of interpretation, literal meaning or minimal propositions form little or no part, and if then with the advice to reject them. In Literal Meaning (2004) Recanati writes that "there is no level of meaning which is both (i) propositional (truth-evaluable) and (ii) minimalist, that is, unaffected by top-down factors" (Recanati 2004: 90). Top-down factors are those contextual contributions, which are not urged by an expression on the sentence's level, for instance, by an indexical expression - they are context-driven. The paradigm cases for top-down factors are free-enrichment (the interpretation is made more specific), semantic transfer (transfer of reference) and loosening (the application of a predicate is widened). What should not be neglected here is that even top-down factors operate on something. How can contextualists then reject literal meaning?

In Literal Meaning Recanati addresses this argument against contextualism that "we must treat modulation effects as arising from the interaction of context with context-independent meanings" (Recanati 2004: 151). He rejects this criticism by pointing out that (i) words do contribute to an utterance's meaning but (ii) the contributions are "not 'meaning' in the traditional sense: it is what I called the 'semantic potential' of words. [...] Context does not do everything, even on the most extreme form of Contextualism" (Recanati 2004: 152). In order to keep up any relevance of the words used in a context without falling back to literal meaning, Recanati turns in Literal Meaning to the notion of "semantic potential" of a word, which is "the collection of past uses on the basis of which similarities can be established between the source situations (the situation of current concern)" (Recanati 2004: 152). However, it is hard to see how the postulation of the notion semantic potential makes sense at all. It is even harder to see how it can be integrated in a contextualist theory, since what is the semantic potential of a word if it can mean, provided enough background and sufficient contextual contributions, even the contrary of what words are used for? At any rate, it cannot be used to 
explain the meaning of mentioned sentences. But what this shows is that it is central to contextualism that what is literally expressed by a sentence falls apart from the proposition expressed by uttering that sentence (again: if this makes sense at all).

\section{Standing meaning and occasion meaning}

This point can be made more explicitly if we turn on Recanati's idea discussed in Truth-Conditional Pragmatics (2010). There he follows Searle and distinguishes between "the standing meaning of the expression (verb of adjective) as fixed by the semantic conventions of the language, and the occasion meaning which the expression assumes on a particular occurrence" (Recanati 2010: 32). He defines the standing meaning of an expression as the meaning, which the word has in isolation, in virtue of the conventions of the language. Contrary to the standing meaning, the occasion meaning is the meaning in a particular linguistic context. Recanati deals in Truth-Conditional Pragmatics with standing meaning in order to save compositionality but for my purpose here this is negligible, since standing meaning could be treated as something more general, i.e., in this context it could be identified with mentioned sentences. Although this does not seem completely unproblematic, it becomes plausible if we consider the contrary: It would mean that the meaning of a mentioned sentence has nothing to do with the actual use of a sentence.

Recanati defines standing meaning as the meaning a word has in isolation and refers to conventional meaning in order to fix it: "The standing meaning is the meaning which the word (type) has in isolation, in virtue of the conventions of the language" (Recanati 2010: 33). First of all, it is odd that Recanati as a contextualist falls back to conventions or conventional meaning at all unless the notion of convention is weakened in such a way that it merely means that a word means what it means. Later he again follows a suggestion by Searle assuming the standing meaning of a word as a function: "The semantic contribution of the verb 'cut' is not directly the process of mowing but something more abstract, namely a function which takes that process as a value for a given argument (the grass)" (Recanati 2010: 34). Recanati introduces the notion of function in order to bridge the gap between the occasion meaning and the standing meaning. The direction how to derive either occasion meaning or standing meaning is of little importance. What is more important is that an understanding of standing meaning as functional leading to the occasion meaning in a context leaves out completely the standing meaning. Take Recanati's example: cut can be understood as CUT IN THE MANNER OF $X$ whereby $X$ stands for the grammatical object of $c u t$, e.g. grass or cake. But what have CUT IN THE MANNER OF GRASS and CUT IN THE MANNER OF 
Lodz Papers in Pragmatics 7.2 (2011)/Special Issue on Context and Contextualism: 280-290 DOI: $10.2478 / \mathrm{v} 10016-011-0015-4$

CAKE in common, is unexplained. Arguing that it is the function, which is common to both standing meanings overrates the normative force of functions. Davidson alludes to this in "Truth and Meaning":

Ask, for example, for the meaning of 'Theaetetus flies'. A Fregean answer might go something like this: given the meaning of 'Theaetetus' as argument, the meaning of 'flies' yields the meaning of 'Theaetetus flies' as values. The vacuity of this answer is obvious. (Davidson 1967: 20)

By the same token, a functional account in this context ignores all the problems such an analysis would entail, for instance, the Caesar is a prime-number problem or Wittgenstein's rule-following-paradox.

I think it is of little importance how processes are named and grouped to bridge the gaps between the parts a contextualist theory of meaning is composed of. It is essential to account not only for the bridge-principles, but for the parts, i.e., semantic potential or standing meaning on the one side and utterance or occasion meaning on the other side. Otherwise, I do not see how it is possible to maintain a difference between what is conveyed with an uttered sentence and the sentence itself. Considering the universality of functions introduced in order to bridge the gaps between the levels of meaning, I conclude that contextualist's theories cannot account for the distinction.

\section{Conclusion}

What follows from these considerations for the use-mention distinction? I am not sure whether the identification of minimal propositions with the meaning of mentioned sentences can be worked out. Since this is not the focus of my discussion here I refrain from giving a definitive answer. The issue with contextualism is different: If it is a hallmark of these theories that what is said by an utterance falls apart from linguistic meaning or sentence's meaning, then for all levels (of meaning) it must be possible to draw a distinction akin to the usemention distinction as outlined at the beginning.

\section{References}

Cappelen, Herman and Ernest Lepore. 2005. Insensitive Semantics: A Defense of Semantic Minimalism and Speech Act Pluralism. Oxford: Blackwell.

Davidson, Donald. 2001. Truth and Meaning (1967). In: Donald Davidson (ed.), Inquiries into Truth and Interpretation. Oxford: Clarendon Press. 17-36. 
Recanati, François. 2001. Open Quotation. Mind 110/439. 637-687.

-. 2004. Literal Meaning. Cambridge: Cambridge University Press.

-. 2005. Meaning and Ostension. From Putnam's Semantics to Contextualism. Talk given at the conference "Les defies d'Hilary Putnam", 22-24 March 2005. Paris. http://jeannicod.ccsd.cnrs.fr/ijn_00000599_v1/.

—. 2010. Truth-Conditional Pragmatics. Oxford: Oxford University Press.

Wittgenstein, Ludwig. 1974. Philosophical Grammar. Oxford: Blackwell.

\begin{abstract}
About the Author
Štefan Riegelnik is a lecturer at the Vienna University of Economics. He teaches epistemology, philosophy of language and ethics. His areas of research interest are theories of language and epistemology.
\end{abstract}

